\title{
NARRATIVAS MAXAKALI: \\ POSSIBILIDADES PARA O ENSINO DE CULTURA E HISTÓRIA INDÍGENA
}

Pablo Luiz de Oliveira Lima*

Nayara Silva de Carie ${ }^{* *}$

RESUMO: O povo Maxakali enfrentou a colonização e resiste, até os dias de hoje, com a força de seus hábitos culturais. As narrativas indígenas são fontes ricas para o ensino de história, desde que trabalhadas adequadamente, respeitando a alteridade cultural, os diferentes conjuntos de valores, crenças e organização social dos povos indígenas. Este trabalho propõe um diálogo entre narrativas indígenas e teorias sobre a narrativa histórica. A presença de narrativas indígenas no ensino de História está relacionada às mudanças que ocorreram no ensino dessa disciplina a partir da década de 1980, com a instituição dos direitos indígenas constitucionais, novos parâmetros curriculares e uma legislação que tornou obrigatório o ensino de história e cultura indígenas na educação básica brasileira (Lei n 11.645/08). A utilização de narrativas indígenas no ensino de história, além de levar os alunos a compreenderem melhor as culturas indígenas, pode levá-los a percepções ampliadas sobre a sua própria cultura.

Palavras-chave: Narrativas; Maxakali; Ensino de História; História Indígena.

\footnotetext{
* Doutor em História pela Universidade Federal de Minas Gerais (UFMG); Professor adjunto do Departamento de Métodos e Técnicas de Ensino da Faculdade de Educação (FaE) da Universidade Federal de Minas Gerais (UFMG). E-mail: plolima@yahoo.com * * Doutoranda em Educacão (FaE/UFMG). Professora na Rede Estadual de Educação de Minas Gerais e do Centro Federal de Educação Tecnológica (CEFET). E-mail: nayaracario@yahoo.com.br
} 
MAXAKALI NARRATIVES:

POSSIBILITIES FOR THE TEACHING OF INDIGENOUS CULTURE AND HISTORY

ABSTRACT: The Maxakali people faced colonization and have resisted to present days, with the strength of their cultural habits. Indigenous narratives are rich sources for the teaching of history as long as they are worked adequately, while respecting cultural alterity and the different systems of values, beliefs and social organizations of indigenous peoples. It is proposed a dialogue between indigenous narratives and theories on historical narratives. The presence of indigenous narratives in the teaching of History is related with changes that occurred in the teaching of this subject since the 1980s, with the institution of constitutional indigenous rights, new curricular parameters and a legislation that obligates the teaching of indigenous history and culture in the Brazilian basic education (Federal Law no. 11645/08). The use of indigenous narratives in the teaching of history can lead students to a better understanding about indigenous cultures, as well as to a broader perception of their own culture.

Keywords: Narratives; Maxakali; History Teaching; Indigenous History.

\section{Introdução}

"Este livro conta histórias que aconteceram com os antepassados e o que aconteceu antigamente. Nós não sabemos as histórias dos antepassados, mas eles contam para nós e mostram os desenhos. Os desenhos mostram o que aconteceu e a gente vê e diz: Ah! Foi assim! Agora eu vi. Assim é bom pra todos nós sabermos o que aconteceu. É muito bom pra nós" (MAXAKALI et al., 2005, p.9).

História, narrativa, ensino e aprendizagem são fenômenos interdependentes. Estão juntos nos processos de formação humana e educação das culturas indígenas no continente americano, das culturas nativas da Eurásia, África e das ilhas do Pacífico. Nas palavras do professor indígena Rafael Maxakali, citadas, como epígrafe, acima, percebe-se a relevância da narrativa escrita e visual para a educação indígena Maxakali, em especial, no trabalho com a área do conhecimento histórico. A memória dos mais velhos é comunicada por meio de narrativas orais e visuais que guardam a marca do testemunho. Na língua Maxakali, não há distinção entre história e narrativa. Neste artigo, serão apresentadas algumas possibilidades de trabalho com narrativas de memória Maxakali no ensino de História. Primeiramente, será analisada a presença dessas narrativas em um museu da cidade de Belo Horizonte, cuja maioria do público é constituída por estudantes da Educação Básica. Em seguida, será abordada a 
relação entre as narrativas indígenas e as concepções moderna e pósmoderna de História. Será realizada uma análise da temática indígena na legislação que orienta o trabalho com o ensino de História escolar, desde os Parâmetros Curriculares Nacionais (PCN), de 1997, passando pela Lei $n^{\circ} 11.645 / 2008$, que tornou obrigatório o ensino de História e Cultura Indígena, e pela Matriz de Referência para o Exame Nacional do Ensino Médio (ENEM), de 2009. Discutir-se-á, então, como as mudanças na historiografia e na legislação influenciaram o ensino de História escolar na virada do século XX ao XXI. E, por fim, será empreendida uma análise sobre as possibilidades de ensino a partir das narrativas Maxakali, entendidas como fontes ricas para o ensino-aprendizagem de História.

\section{A narrativa Maxakali no museu}

A palavra Maxakali ãgtux corresponde tanto ao verbo português narrar, quanto ao substantivo português (de origem grega) história. O povo Maxakali habita o território de Minas Gerais há milhares de anos. Sua cultura é marcada por hábitos de longuíssimas durações, que enfrentaram inúmeras transformações. Com a colonização portuguesa, os Maxakali foram forçados a realizar migrações, o que exigiu a aprendizagem sobre novos territórios e o desenvolvimento de novas técnicas de caça, coleta e agricultura necessárias para a sobrevivência e reprodução social.

De acordo com a Arqueologia, o território mineiro é habitado há, aproximadamente, 12 mil anos (PROUS, 2007, p.7). Os povos indígenas que habitam esse território, como os Maxakali atuais, podem ser considerados descendentes desses primeiros habitantes. Assim, os Maxakali desenvolveram sua cultura ao longo de milênios em contato com outros povos indígenas. A partir da colonização portuguesa, iniciaram os contatos com os europeus e africanos. Apesar de os Maxakali terem enfrentado, desde então, a realidade colonial, ou seja, a perda de seus territórios ancestrais, que foram ocupados pelos colonos, a imposição das leis do Estado português, o desrespeito em relação à sua cultura - eles resistem até os dias de hoje, com a força de sua língua e de seus hábitos culturais.

Atualmente, a língua Maxakali, que pertence à família linguística de mesmo nome, é falada por, aproximadamente, 1.500 pessoas, vivendo em três territórios descontínuos no vale do Rio Mucuri, nordeste de 
Minas Gerais. A maioria do povo Maxakali fala somente a sua própria língua, sendo o português falado fluentemente por apenas alguns membros da etnia, principalmente homens. "As mulheres e crianças falam unicamente palavras esparsas em português, sendo a comunicação entre eles totalmente em seu idioma".' A língua Maxakali passou a ter uma escrita alfabética apenas nos anos de 1960, a partir das pesquisas do casal norteamericano Harold Popovich (linguista) e Frances Popovich (antropóloga), que viveram com os Maxakali entre 1958 e 1987. Na década de 1960, "o linguista Aryon Rodrigues classificou o idioma Maxakali como pertencente ao tronco Macro-Jê, sendo essa classificação aceita atualmente" (MENDES, 2009, p.9).

Hoje, os Maxakali são reconhecidos como povo que contribui para a formação da sociedade brasileira. Um exemplo disso pode ser encontrado no Espaço TIM/UFMG do Conhecimento, museu situado em Belo Horizonte, Minas Gerais, cuja exposição busca representar os povos e culturas que compõem a sociedade mineira. Essa instituição, inaugurada em 2008, possui um caráter cultural, educacional e museológico e foi a primeira a ser inaugurada no circuito cultural da Praça da Liberdade. ${ }^{2}$ Não se autodenomina museu e, sim, espaço de conhecimento, no entanto, utiliza a linguagem museográfica e possui uma exposição que trata de diversos aspectos da história, sociedade e cultura de Minas Gerais.

Assim como ocorre com grande parte dos museus e espaços culturais de exposições na cidade de Belo Horizonte, a maioria do público do Espaço TIM/UFMG do Conhecimento é composta por estudantes da Educação Básica, de escolas públicas e privadas. São alunos de diversas idades que vão ao local, acompanhados por professores de diferentes áreas, e lá encontram uma narrativa museográfica que tenta abordar as mais diversas áreas do conhecimento, sempre se remetendo à população e território de Minas Gerais.

Em determinado ponto de sua narrativa museológica, há um lugar dedicado aos diferentes mitos de origem das culturas que constituem a sociedade mineira. Essas culturas são colocadas lado a lado, com o mesmo status formal, por meio de uma imagem e de um texto que representam as suas versões sobre a formação do mundo e a criação dos seres humanos. São apresentadas quatro narrativas referentes aos mitos de origem greco-romana, cristã, africana e indígena. Nesse último caso, os indígenas são representados pelos Maxakali, com a seguinte narrativa: 


\section{Cosmogonia Maxakali}

Havia, antes, apenas um homem na Terra. Um dia, ele foi tomar água e viu, no barreiro, uma forma de mulher. Fez sexo com ela e foi embora. Quando olhou para trás, viu uma menina que o chamou de pai. Ele disse para ela se casar com o lobo, e este a desejou só para si. Levou-a para casa. Lá, ele a escondeu dentro de uma bolsa de couro. De noite, ele a tirava e dormia com ela. De manhã, ele tornava a guardá-la. Mas os yamiys, os espíritos, traçaram um plano para o coelho vigiar o casal: ele tomaria mel até ficar tonto, fingindo doença, e sairia de casa em casa pedindo abrigo para dormir, mas ninguém o aceitaria. O lobo, porém, o convidou para sua casa. O coelho fingia dormir, mas vigiava o namoro do lobo com sua mulher. Percebendo, o lobo pegou um pau em brasa e o colocou nas costas do coelho. Este não se mexeu e o lobo achou que ele tinha morrido. Acreditando-se sozinho, tirou sua mulher de dentro da bolsa em que a escondia. O coelho, imediatamente, saiu gritando e contou para todos o namoro que acabara de descobrir. O lobo pegou a esposa e jogou-a para o alto. Ela agarrou-se num galho de árvore e ficou lá em cima. O lobo abraçou-se ao tronco e falou que não tinha mulher. Mas o coelho afirmava que estava vendo o colar, a pulseira... Os outros lobos, então, juntaram-se para pegar a mulher dele à noite. Derrubaram-na de lá, cortaramna em pedacinhos e dependuraram-na nos galhos das árvores. Desses pedaços surgiu o restante do povo. O lobo, sem mulher, passou a viver triste na Kuxex [a casa da religião dos homens ${ }^{3}$. Todo dia, saía para o pátio, dançando e cantando. Os yamiys, então, chamaram o tatu para cavar o chão, deixando apenas uma fina camada de terra. Quando o lobo passou, a terra rompeu-se, e ele caiu no buraco. O coelho apareceu para ajudar o lobo a sair da armadilha. Ficaram amigos e vivem juntos. Quando há ritual, eles saem da Kuxex, cantando e dançando. As mulheres oferecem comida ao lobo e o coelho é quem leva (Texto da exposição do Espaço TIM/UFMG do Conhecimento, em Belo Horizonte/MG).

Esse texto museográfico é a tradução de uma história Maxakali que explica o surgimento do povo a partir de um Maxakali primevo, em um tempo mítico. A partir de uma relação sexual entre o Maxakali primevo e a terra, origina-se a primeira mulher. Ela é esposada pelo lobo em segredo, e este a guarda em uma bolsa. Os espíritos - yamiys - conduzem o coelho a revelar a relação secreta do lobo com a mulher. O lobo tenta esconder sua esposa, mas os outros lobos acabam pegando-a e cortandoa em muitos pedaços. Esses pedaços deram origem ao povo Maxakali. Homem, terra, mulher, lobo, yamiys e povo são os sujeitos da narrativa. Relacionam-se em um tempo sem cronologia, tratando do início do povo Maxakali. 
A princípio, a inclusão da narrativa Maxakali entre a greco-romana e a cristã pode ser vista como uma tentativa de colocar esses diferentes mitos de origem no mesmo nível de importância para a formação cultural mineira. Porém, é possível imaginar o estranhamento de estudantes, professores e do público não indígena em geral, membros de uma sociedade predominantemente cristã, ao compararem a versão bíblica com a menos conhecida versão Maxakali sobre a origem da humanidade. É importante questionar como um público que está muito acostumado com a explicação bíblica lê e se apropria dessa narrativa, considerando a maneira como a mesma está exibida no Espaço TIM/UFMG do Conhecimento. Será que, assim apresentada, essa narrativa Maxakali não acaba por passar uma imagem exótica dos povos indígenas? Não se corre o risco de perpetuar uma imagem estereotipada e incompreensível a respeito desses povos? Não seria necessário que a exposição apresentasse mais elementos históricos e culturais sobre o povo Maxakali para que essa narrativa fosse compreendida de forma contextualizada, dentro da lógica cultural dos próprios Maxakali?

As narrativas indígenas podem ser consideradas fontes ricas para o ensino de História, desde que trabalhadas de forma adequada, ou seja, respeitando a alteridade cultural, os diferentes conjuntos de valores, crenças e organização social desses povos. Neste artigo, serão abordadas algumas possibilidades do uso de narrativas de autoria indígena no ensinoaprendizagem de História na Educação Básica. O objetivo é buscar conhecer as narrativas dos próprios indígenas para que possam ser compartilhadas por estudantes de diferentes culturas, uma vez que a narrativa está presente em todas as sociedades. Como observa Barthes (2001), a narrativa se inicia com a própria história da humanidade, estando presente em todos os tempos, lugares e sociedades, não havendo, portanto, nenhum povo sem narrativa.

\section{Narrativa e História}

Esta parte do artigo tenta contextualizar a discussão sobre as narrativas indígenas Maxakali no campo da História. Propõe-se, assim, um diálogo entre algumas narrativas de memória e história indígenas e teorias sobre a narrativa histórica desenvolvidas pela historiografia. Essa 
opção se justifica pela busca de uma construção intercultural entre conhecimentos indígenas e não indígenas, uma vez que não é possível pensar no isolamento ou na ausência de comunicação entre os diversos povos. Assim, pretende-se apontar a contribuição das narrativas de memória indígena para o ensino de História.

Narrativas de memória indígena são aquelas que tratam da relação passado-presente, que dão explicações sobre as origens de um povo e aspectos da cultura a partir da memória coletiva de uma comunidade. Optou-se, aqui, por tratar as categorias de mito e lenda como narrativas de memória. $\mathrm{Na}$ medida em que essas narrativas de memória são tentativas de se entender o mundo em que se vive, elas dizem muito sobre a perspectiva por meio da qual os povos indígenas interpretam a sua própria realidade.

Para o historiador Jacques Le Goff (1990), a História é uma narrativa construída sobre sinais deixados pelas atividades humanas ao longo do tempo, ou seja, as chamadas fontes históricas. No entanto, as fontes históricas não falam por si próprias, portanto, precisam sempre ser interpretadas. O trabalho do historiador consiste na análise e interpretação das fontes para construir uma narrativa histórica. É possível situar um debate no campo da narrativa histórica entre a concepção moderna e a concepção pós-moderna de História, sendo esta última marcada pela emergência das narrativas indígenas, como as de autoria Maxakali.

A concepção moderna de história se consolidou na Europa durante o século XIX, por meio dos trabalhos de Leopold Ranke, Johan Droysen e de outros "cientistas" sociais. Nesse período, a História estavase constituindo como campo disciplinar independente dentro das universidades e, portanto, precisava construir uma identidade que a legitimasse como ciência. Essa legitimação passava também por uma separação entre História e Literatura, verdade e ficção. Buscava-se a cientificidade no trabalho do historiador por meio da construção de métodos de análise crítica das fontes que pudessem revelar "a verdade" a partir de uma interpretação "correta". Nessa concepção de História, uma fonte histórica deveria possuir autenticidade, integridade e confiabilidade, ou seja, refutava-se, explicitamente, qualquer fonte oriunda da tradição oral e da memória, consideradas demasiadamente subjetivas. As fontes consideradas legítimas eram as de caráter oficial, produzidas pelos órgãos de Estado, como leis, tratados diplomáticos, discursos governamentais, levantamentos 
demográficos, registros de nascimento e óbito, etc. Acreditava-se, também, na objetividade do historiador. Assim, a História seria um tipo de ciência.

A partir da análise de fontes escritas, o trabalho dos historiadores europeus do século XIX produziu narrativas minuciosas, cuidadosas e sistemáticas. Construíram, assim, uma ciência calcada na singularidade dos vários fatos encontrados na análise das fontes e nos fenômenos singulares. A narrativa histórica moderna tinha o objetivo de produzir uma totalidade articulada pelo exercício de análise e busca de coerência entre evidências e discurso.

Nas narrativas históricas modernas, há uma relação especial entre a cronologia e o enredo. A História seria, assim, uma narrativa cronológica. A narrativa histórica do século XIX, pelo método crítico, segue um enredo totalizante, que aceita várias interrupções e é aberta à incorporação de novas informações à trama complexa dos "fatos". Esse tipo de discurso narrativo não aceita fios soltos. Ele busca interligar rigorosamente todos os dados mais ou menos fragmentários em um discurso sem espaço para a casualidade. Buscava-se uma narrativa que representasse o mundo de forma perfeitamente articulada e consistente. A imprevisibilidade, de certa forma, aparece no interior da narrativa do século XIX, mas reduzida às suas dimensões mínimas.

Ao longo do século XX, e ainda hoje, a concepção moderna de História tem recebido críticas formuladas pela própria academia, influenciada pela Antropologia e pelos Estudos Culturais. Michel Foucault é um desses críticos pós-estruturalistas que buscou substituir o que ele chama de metanarrativa (moderna, ou seja, uma narrativa totalizante, com um sentido único, universal) por narrativas locais, mantendo a estrutura narrativa, mas negando a ideia de totalidade, progresso ou evolução social, bem como a possibilidade de uma objetividade na análise histórica. Paul Ricoeur, expoente nos estudos sobre a narrativa histórica, também critica a concepção moderna de narrativa. Para ele, ao contrário do que defendiam os historiadores do século XIX, a História não é objetiva, mas “essencialmente equívoca” (RICOEUR apud LE GOFF, 1990, p.21), ou seja, depende da interpretação que pode variar conforme a formação do historiador, os seus objetivos, o conjunto de fontes à qual tem acesso, etc.

Michel Foucault critica a visão moderna da narrativa, defendendo uma perspectiva arqueológica fragmentária e não totalizante. A 
Arqueologia do saber, inserida na análise do discurso, busca compreender os sistemas de produção, regulação e circulação do saber, as regras de produção e circulação de um ou mais discursos em um dado período. Valoriza, assim, os enredos locais, restritos a espaços específicos ou a conjuntos de relações internas ao discurso em narrativas microcentradas (LE GOFF, 1990, p.105).

Outra diferença demarcada por Foucault refere-se à relação com as fontes. Se, para a concepção moderna de História, as fontes externas à memória humana (documentos escritos, arqueológicos) possuem um privilégio científico, devido a uma suposta objetividade, para as Histórias indígenas, as fontes mentais (a própria memória de quem narra) são tão ou mais - legítimas que as fontes externas.

\section{0 ensino de História Indígena na legislação brasileira}

Em 2008, o Congresso Nacional brasileiro aprovou a Lei $n^{\circ}$ 11.645, que incluiu a obrigatoriedade do ensino de "História e Cultura Afro-Brasileira e Indígena" no currículo oficial da Educação Básica, pública e privada. ${ }^{4}$ A lei estabelece que o "conteúdo programático" referente a essa temática deve abordar

[...] diversos aspectos da história que caracterizam a formação da população brasileira, a partir desses dois grupos étnicos [afro-brasileiros e indígenas], tais como o estudo da história da África e dos africanos, a luta dos negros e dos povos indígenas no Brasil, a cultura negra e indígena brasileira e o negro e o índio na formação da sociedade nacional, resgatando suas contribuições nas áreas social, econômica e política, pertinentes à história do Brasil (BRASIL, Lei $\mathrm{n}^{\circ} 11.645$, de 10/03/2008).

O texto da lei também indica que os conteúdos referentes à História e Cultura Afro-Brasileira e dos povos indígenas deverão ser trabalhados por todas as áreas do conhecimento, mas, "em especial, nas áreas de Educação Artística, de Literatura e História Indígenas” (BRASIL, Lei $n^{\circ} 11.645$, de 10/03/2008).

Essa lei pode ser criticada em, pelo menos, dois aspectos. Um primeiro problema é que, nesse documento, as culturas afro-brasileiras e indígenas são consideradas pertinentes apenas para a compreensão e o 
estudo da História "Nacional". Isso desconsidera o estudo de História Indígena anterior à construção da nação brasileira. Um segundo problema é a classificação dos afro-brasileiros e indígenas como sendo dois grupos étnicos homogêneos, quando, na realidade, existe uma grande diversidade étnica entre os povos originários do continente africano e americano. Apesar dessas críticas, a lei tem como ponto positivo trazer as temáticas afro-brasileira e indígena para o campo da educação escolar, possibilitando uma aproximação entre História, Literatura e Artes.

No entanto, os Parâmetros Curriculares Nacionais (PCN), publicados em 1997, já apresentavam o estudo dos povos indígenas, seu modo de vida, costumes, religiosidade, organização social como temáticas pertinentes ao ensino de História. É o que se pode ver em um dos objetivos dos PCNs para o primeiro ciclo do Ensino Fundamental, em que os alunos devem ser capazes de "caracterizar o modo de vida de uma coletividade indígena, que vive ou viveu na região, distinguindo suas dimensões econômicas, sociais, culturais, artísticas e religiosas"; "identificar diferenças culturais entre o modo de vida de sua localidade e o da comunidade indígena estudada" (BRASIL, 1997, p.40). Além dos objetivos, a temática indígena está presente como conteúdo de História para o primeiro ciclo, compondo o eixo temático "História Local e do Cotidiano". Os PCNs elegem os seguintes aspectos para o trabalho com a História Local e do Cotidiano que se relacionam às comunidades indígenas:

Identificação do grupo indígena da região e estudo do seu modo de vida social, econômico, cultural, político, religioso e artístico:

- o território que habitam e que já habitaram, organização das famílias e parentesco, a produção e distribuição de alimentos, a divisão de trabalho entre os sexos e as idades, as moradias e a organização do espaço, os rituais culturais e religiosos, as relações materiais e simbólicas com a natureza (os animais e a flora), a língua falada, as vestimentas, os hábitos cotidianos de higiene, a medicina, as técnicas de produção de artefatos, as técnicas de coleta ou de produção de alimentos, a delimitação do território geográfico e de domínio da comunidade, os espaços que são públicos e os espaços considerados privados, as transformações sofridas pela cultura no contato com outros povos, as relações de amizade, trocas ou identidade com outras comunidades indígenas, as brincadeiras e as rotinas das mulheres, dos homens, das crianças e dos velhos, a medição do tempo, o contar histórias, as crenças, lendas e mitos de origem, as manifestações artísticas, como músicas, desenhos, artesanato, danças.

Identificação de semelhanças e diferenças entre o modo de vida da localidade dos alunos e da cultura indígena: 
- existem vários aspectos da coletividade dos alunos que são diferentes do modo de vida da comunidade indígena estudada: na ocupação do território, no relacionamento com a natureza (produção de alimentos, uso da água, do solo e da vegetação, mitos, medicina, preservação), nas construções de moradias (materiais, técnicas, construtores, distribuição e uso do espaço interno), na divisão de tarefas entre as pessoas na realização de trabalhos, nos tipos e confecção de vestimentas, nos tipos de lazer, na religiosidade, nos mitos de origem, nas técnicas de fabricação e uso de instrumentos nas mais diversas atividades de trabalho, no uso do espaço geográfico, nos hábitos de higiene, nos meios de comunicação, nos meios de transporte, nos diferentes modos de medir o tempo (BRASIL, 1997, p.42-43).

O trabalho com as narrativas indígenas como fonte histórica pode-se relacionar a vários objetivos presentes nos $\mathrm{PCNs}$ do $6^{\circ}$ ao $9^{\circ}$ ano do Ensino Fundamental, pois as narrativas indígenas se constituem como fontes históricas extremamente ricas para a compreensão do povo que as construiu. Isso ocorre porque, como explica Brockmeier e Harré (2003), as narrativas são modos específicos de constituição e construção da realidade a partir da perspectiva do que é aceito - ou não - por determinada cultura.

Nesse sentido, entrar em contato com as narrativas de um povo é aproximar-se de sua organização social, cultural, política, econômica, suas visões de mundo e seus conflitos. É desse modo que os objetivos elencados para o terceiro ciclo do Ensino Fundamental de História, nos PCNs, contemplam o trabalho com as narrativas indígenas no ensino de História, haja vista que o trabalho com as narrativas permite:

$[\ldots]$

- conhecer realidades históricas singulares, distinguindo diferentes modos de convivência nelas existentes;

- caracterizar e distinguir relações sociais da cultura com a natureza em diferentes realidades históricas;

- utilizar fontes históricas em suas pesquisas escolares [...] (BRASIL, 1998, p.54).

O trabalho com as narrativas indígenas como documento histórico também pode ser relacionado, mais especificamente, à matriz de competências do ENEM (Exame Nacional do Ensino Médio), no que se refere às competências da área 1 , destinadas a compreender os elementos culturais que constituem as identidades: 
$[\ldots]$

- Interpretar historicamente e/ou geograficamente fontes documentais acerca de aspectos da cultura.

- Comparar pontos de vista expressos em diferentes fontes sobre determinado aspecto da cultura.

- Identificar as manifestações ou representações da diversidade do patrimônio cultural e artístico em diferentes sociedades [...] (BRASIL, 2009).

Além disso, na matriz de referência para o ENEM de 2012, entre as seis áreas de competências elencadas para a matriz de referência das Ciências Humanas e suas Tecnologias, podem-se encontrar, em cinco delas, objetivos que se relacionam ao conhecimento das narrativas indígenas. Nos "Objetos de conhecimento associados às Matrizes de Referência" do ENEM, é explícita a menção à temática indígena no caso das Ciências Humanas e suas Tecnologias, no campo da "Diversidade cultural, conflitos e vida em sociedade": "A Conquista da América. Conflitos entre europeus e indígenas na América colonial. A escravidão e formas de resistência indígena e africana na América. História dos povos indígenas e a formação sociocultural brasileira" (BRASIL, 2012). ${ }^{5}$

Cabe observar que, nesse último caso citado, a temática indígena figura explicitamente apenas no contexto do período colonial e na "formação sociocultural brasileira", e não mais nos processos e períodos subsequentes.

O ensino de História Indígena e o uso de suas narrativas no ensino de História estão relacionados às mudanças que ocorreram no ensino de História nas décadas de 1980 e 1990. De acordo com Anhorn (2003), essas transformações podem ser consideradas como fruto de uma crise na construção da História ensinada na escola, resultado do processo de redemocratização política brasileira, iniciado no final dos anos de 1970. Nesse contexto, a disciplina passou a buscar uma identidade que se adequasse às transformações ocorridas na sociedade brasileira.

Para Fonseca (2003), é também nesse cenário que, no início da década de 1980, estados brasileiros, como São Paulo, Minas Gerais e Rio de Janeiro, passaram a discutir propostas para o ensino de História inspiradas em várias vertentes historiográficas, tais como a História Cultural, a História Social Inglesa, o Materialismo Dialético. A proposta de São Paulo se aproximou mais da linha da Historiografia Social Inglesa, a proposta do Rio de Janeiro, embora não tenha explicitado os fundamentos da propos- 
ta teórica, foi influenciada pelo Materialismo Dialético, pela Historiografia Francesa e pela Historiografia Social Inglesa. Paraná e Santa Catarina se apoiaram nas contribuições da História Cultural, em seus estudos sobre o imaginário, e a proposta de Minas Gerais aproximou-se mais do Materialismo Histórico e do Marxismo Ortodoxo.

Para Anhorn (2003), os programas criados, nesse momento, questionaram fortemente as bases sobre as quais a disciplina se apoiava. O sustentáculo da História ensinada passou a ser adjetivado como tradicional, cujo significado tornou-se sinônimo de positivista. De modo geral, ela pode ser caracterizada pela ênfase nos fatos políticos de curta duração, nos indivíduos que eram identificados como heróis, na concepção linear do tempo, teleologicamente guiado, narrado a partir de uma perspectiva identificada com a verdade absoluta.

Segundo Fonseca (2003), para se contrapor à História tradicional, as propostas curriculares elaboradas em diferentes estados brasileiros, embora distintas, reuniam alguns pontos em comum, tais como a realização do ensino de uma História mais crítica, participativa, dinâmica, rompendo com a linearidade e o etapismo. Buscava-se uma ruptura com a História oficial, e, para isso, era necessário mostrar a perspectiva de diversos sujeitos, dar voz a novos personagens a partir da compreensão de que todos os homens fazem a História e não somente os grandes estadistas ou heróis nacionais. Os fatos históricos passaram a ser relativizados dentro de uma perspectiva interpretativa, possibilitando a coexistência de diversas versões históricas. Em relação à concepção de tempo, surgiu uma diferenciação entre o tempo cronológico e o tempo histórico, sendo o primeiro seqüencial, e o segundo, formado por temporalidades múltiplas, como a sucessão e a simultaneidade. Desse modo, o historiador começa a se colocar novas perguntas, que o leva a formular outros problemas, dos quais participam diferentes sujeitos, que podem ser estudados pelo historiador por meio de diversas fontes distintas dos documentos oficiais.

Tornou-se, então, importante saber o que pensavam e como viviam pessoas das classes trabalhadoras, negros, indígenas, mulheres, crianças, e não apenas os grandes políticos ligados ao poder; para isso, novas fontes, além dos documentos oficiais, passam a ser valorizadas como vigorosas portadoras de informações sobre a presença humana, em variadas situações ao longo do tempo. 
É nesse movimento de ampliação da noção de fontes, sujeitos e tempo histórico na historiografia e que influenciou a História escolar a partir da década de 1980, que as narrativas indígenas se constituem em fontes históricas que têm muito a dizer sobre a cultura, os valores, a visão de mundo, a organização social das sociedades indígenas no passado e no presente. Portanto, a análise de narrativas indígenas no ensino de História, além de levar os alunos a compreenderem melhor as culturas indígenas, pode levá-los, também, a percepções mais ampliadas sobre a sua própria cultura, incluindo a presença indígena nos modos de sociabilidades brasileiros contemporâneos.

Além disso, no contexto do final da década de 1980, o movimento indígena conquistou um espaço na nova Constituinte, resultando na inclusão dos direitos indígenas na nova Constituição Federal, em 1988. De acordo com Ailton Krenak, o movimento indígena, representado pela União das Nações Indígenas, conseguiu dar voz aos interesses dos povos indígenas na nova Constituição (KRENAK, 2012, p.122). O artigo 231 garantiu "aos índios, sua organização social, costumes, línguas, crenças e tradições" (BRASIL, 1988). ${ }^{6}$ Com esse reconhecimento legal, os povos indígenas conquistaram a inclusão de uma educação indígena diferenciada no texto da lei e o estabelecimento de escolas indígenas em seus territórios, algo que já era praticado por muitos povos indígenas. Desde então, muitas iniciativas no âmbito da educação e cultura indígena têm ocorrido, com destaque para a literatura indígena, escrita em português e em línguas indígenas, e a implementação de cursos de formação de professores indígenas em nível médio e superior. Um exemplo disso é o curso de Formação Intercultural de Educadores Indígenas (FIEI), criado na Universidade Federal de Minas Gerais (UFMG) como curso superior regular, em 2010, no contexto do Programa de Apoio a Planos de Reestruturação e Expansão das Universidades Federais (REUNI). Esse curso tem como objetivos a "formação de professores indígenas; elaboração de material didático; [e] melhorar o acesso a carreiras acadêmicas para a população indígena" (LINHART, 2012, p.277). 


\section{As narrativas Maxakali e o ensino de História}

A análise de alguns elementos presentes na narrativa que conta a história do povo Maxakali permite estabelecer algumas relações entre elementos presentes na narrativa e a cultura do povo que a produziu.

Ao ler a narrativa Maxakali exibida no espaço TIM-UFMG do Conhecimento e apresentada no início deste texto, o leitor não Maxakali pode sentir um certo estranhamento na maneira como os acontecimentos são encadeados. A partir da perspectiva ocidental, na narrativa, parece haver mais de um clímax, o que faz suspeitar que várias histórias estejam sendo contadas dentro de uma mesma narrativa. Assim, se a atenção for direcionada para outros aspectos da história do surgimento do povo Maxakali, é provável que se encontrem narrativas que expliquem, por exemplo, o surgimento da mulher, quando o homem vê, no barreiro, uma forma feminina, tem relações sexuais com ela e desse encontro nasce uma filha. A mesma narrativa poderia contar sobre o que ocorre quando o lobo desejou ter uma mulher só para ele. Ou pode apontar, ainda, para a influência dos espíritos na vida dos homens.

Coelho (2003), ao estudar lendas indígenas da Amazônia, parece encontrar uma estrutura de narrativa semelhante à do surgimento do povo Maxakali, em que o texto não apresenta um marcador claro para anunciar o início, o clímax e o desfecho das narrativas, como na maioria das narrativas do Ocidente. Nestas, de modo geral, há o predomínio do modelo de estrutura narrativa estudado por Labov (1967), no qual a macroestrutura narrativa é constituída por um resumo da história, geralmente, de uma ou duas cláusulas; uma orientação em relação a lugar e tempo; uma complicação, que é o desenvolvimento da narrativa, ordenada temporalmente; uma resolução, que é o desenlace dos acontecimentos; uma avaliação, que revela a atitude do narrador em relação à narrativa; e uma coda, que consiste em um mecanismo funcional que faz com que a perspectiva verbal volte ao momento presente.

Segundo Coelho:

[...] muitas vezes, essas lendas nos parecem estranhas justamente por romperem com a expectativa do leitor da cultura ocidental, que está acostumado a ler textos em que a complicação, obrigatoriamente, vem acompanhada de uma resolução. Nelas, a pessoa do personagem varia, os episódios nem sem- 
pre apresentam uma ligação causal explícita, e a organização nos parece obscura (COELHO, 2003, p.132).

Pode-se perceber, na narrativa que conta o surgimento do povo Maxakali, a integração do homem com a natureza, em várias passagens, dentre as quais se pode citar aquela em que o homem vê uma forma de mulher no barreiro e mantém relações sexuais com ela, e, dessa união, nasce uma menina. Outro exemplo de integração entre seres humanos e a natureza ocorre quando o homem diz à filha para se casar com o lobo. Não há uma hierarquia entre homem, terra e animais.

Encontra-se, na "Cosmogonia Maxakali", outro aspecto que parece ser o caráter comunitário da cultura Maxakali. O lobo, ao esconder a mulher dos outros animais, tornou-se alvo de suspeitas, e os yamiys, que são seres do mundo espiritual, instruíram o coelho a seguir o lobo e descobrir o que estava escondendo. Nesse sentido, esconder algo do restante do grupo e tomá-lo só para si parece não ser bem visto pela comunidade, por isso a esposa do lobo acaba sendo morta e dividida em muitas partes, que darão origem ao povo Maxakali. Esse aspecto da história pode fazer referência à existência de um modo de vida comunitário na sociedade Maxakali.

Percebe-se também a presença e a interferência do mundo espiritual na vida dos homens. Os yamiys, que são seres do mundo espiritual, ao instruírem o coelho a trazer à vista o que o lobo escondia dos outros animais, parecem ter atuado no sentido de restabelecer o equilíbrio da sociedade comunitária. Pode-se ver aí também que, ao perder a sua mulher, o lobo foi castigado, mas isso ocorreu por algo maior: a manutenção da sociedade comunitária. Nesse sentido, verifica-se também o caráter pedagógico dessa narrativa. Segundo Bicalho (2000), as narrativas Maxakali podem representar certos padrões de comportamento ou conduta social. Coelho (2003), ao analisar as narrativas de índios da Amazônia, também observa narrativas que reiteram formas de viver em sociedade em detrimento de outras. Nas palavras da autora:

Assim, vemos que esses textos expressam várias formas de proibição que pesam sobre o comportamento social na cultura indígena. Parece-nos, então, ser possível afirmar que esses textos constituem-se em lugares de encenação da memória coletiva, pois são construídas de maneira a reiterar determinados conteúdos e valores morais, ao mesmo tempo em que 
podem questionar as maneiras básicas da vida em sociedade (COELHO, 2003, p.87).

Ao observar as narrativas também é possível perceber que não há uma polarização entre bem e mal, entre protagonista e antagonista. $\mathrm{O}$ coelho persegue o lobo durante quase toda a história e torna-se um dos responsáveis pela morte de sua esposa. No entanto, esse mesmo coelho salva o lobo de uma armadilha, quando o lobo cai no buraco feito pelo tatu. Essa ação do coelho estabelece uma relação de amizade com o lobo. É importante ressaltar que a armadilha em que o lobo cai também foi uma interferência dos yamiys, que pediram ao tatu para cavar um buraco no caminho por onde o lobo passava. Nesse sentido, essa também parece ter sido uma estratégia utilizada pelos yamiys para restabelecer o equilíbrio na comunidade, por meio do restabelecimento das relações entre seus membros. Dessa maneira, o aparente mal que os yamiys causaram ao lobo e à sua esposa revelou ser um bem para a comunidade, que culminou na conservação do espírito comunitário da sociedade e no surgimento do povo Maxakali.

Esse exercício de análise da narrativa leva a compreender melhor a sociedade que a produziu. A partir de sua leitura, foi possível identificar uma maneira diferente de narrar e ensinar História. Ao se analisar a narrativa do surgimento do povo Maxakali, observa-se que esta aborda temáticas que estão presentes em diversas sociedades, dentre elas se podendo citar a relação do homem com a natureza, com seus pares e com os seres espirituais. Dessa forma, foi possível voltar o olhar para o modo como a sociedade atual lida com essas questões, interrogá-la e entendê-la um pouco mais. E, nesse sentido, aprender sobre o outro significaria aprender mais sobre nós mesmos.

\section{Considerações finais}

As narrativas de autoria indígena podem ser fontes para o estudo da História Indígena. No âmbito da educação escolar indígena, essas narrativas exercem funções que estão relacionadas, dentre outros aspectos, à memória e à transmissão de saberes dentro da lógica da cultura indígena. Do ponto de vista dos indígenas, essas narrativas são tão ou 
mais legítimas que os conhecimentos construídos "cientificamente", a partir de uma ótica ocidental. Mas sua utilização por parte da educação não indígena requer um exercício de descentramento cultural para que essas narrativas não sejam apropriadas como simplesmente míticas ou exóticas.

É necessário superar o preconceito contra os povos indígenas, que se reveste ora pela perspectiva abertamente racista, ora pela perspectiva do bom selvagem. Essa superação pode dar-se por meio de uma prática viável: ouvir, ler e conhecer as histórias produzidas pelos próprios indígenas. Assim, professores e alunos não indígenas conhecerão mais as sociedades indígenas, suas narrativas, suas histórias, suas trajetórias e seus valores culturais. Conhecendo essas outras narrativas, que possuem outras lógicas, será possível aprender mais sobre o outro e sobre nós mesmos, em um exercício de desnaturalização da forma que indígenas e não indígenas contam suas próprias histórias.

Os autores e adeptos de formas pós-modernas de conhecimento histórico desconfiam de qualquer "grande narrativa" que invoca a "voz masculina" da abstração e universalização. Desse modo, rejeitam as macroteorias positivistas ou "grandes narrativas de legitimação" e dão lugar a microteorias que lidam com a natureza da diferença. $\mathrm{O}$ tom geral de tais teorias sinaliza um movimento de afastamento em relação à certeza e aos efeitos totalizantes das grandes narrativas. Nesse espaço teórico, "as questões estão constantemente se movendo e não se consegue definir, concluir, ou encerrar... é uma práxis da incerteza" (LATHER, 1998, p.488). O objetivo de tais teorias pós-modernas e pós-estruturalistas é problematizar e desconstruir as presunções masculinas, patriarcais e ocidentais das teorias modernistas e seus projetos universalizantes.

$\mathrm{Na}$ medida em que teorizam contra a "certeza", os pós-modernos tendem a defender uma pedagogia negativa, mais identificada como oposição do que como proposição. O desconforto em aceitar qualquer afirmação e reivindicação universal vem da noção pós-moderna de que o mundo é "muito complexo, a gama de visões muito ampla, a diversidade de preocupações muito diferenciada para imaginar que possa haver ainda alguma simples unanimidade de objetivos ou interesses que [nos] unifique" (SHAPIRO, 1995, p.20). As implicações de tal mundo para educadores críticos, de acordo com Svi Shapiro, é lutar "por um discurso público que não privilegie a um grupo; que busque incluir as experiências, neces- 
sidades, esperanças e comunicar-se com um amplo espectro de pessoas na nossa sociedade" (SHAPIRO,1995, p.32). Em outras palavras, os pósmodernos defendem que a multiplicidade do mundo requer um imaginário político que seja reflexivo e indeterminado como é o imaginário social.

Dessa forma, rejeitam a validade de grandes narrativas por perceberem-nas como estreitas demais e, portanto, insuficientes para se imaginar uma nova realidade social. Como escreve Shapiro:

A política que surge da fluidez e complexidade da identidade na América contemporânea não nega, e isto deve ser enfatizado, as lutas historicamente importantes... Nosso objetivo, no entanto, é oferecer uma linguagem educacional - e, em seguida, um projeto - que possa ser o mais inclusivo possível, reconhecendo o maior alcance possível de lutas e preocupações humanas (SHAPIRO, 1995, p.29-30).

Em outras palavras, os pós-modernos propõem uma "práxis da indecisão" e resistem aos impulsos modernos que privilegiam "a contenção no lugar do excesso, o pensamento sobre a emoção, a estrutura no lugar do movimento, a linearidade causal sobre a complexidade, e a intenção sobre as capacidades agregadas" (LATHER, 1998, p.497). Ao fazê-lo, buscam recolocar a "única e verdadeira história" do discurso universalista com uma "práxis não-reducionista que lança a promessa de uma prática sobre um chão em movimento" (LATHER, 1998, p.497). Porém, como observam acadêmicos marxistas, há uma ausência de propostas emancipatórias no campo pós-moderno, como a luta contra a exploração capitalista. Para Peter McLaren (apud GRANDE, 2003), em seu esforço de tentar ser tudo para todos, as teorias pós-modernas têm valorizado uma gama ampla de pedagogias em nome da diversidade. Nesse processo, vozes antes silenciadas apresentam outras experiências humanas que muito enriquecem a compreensão histórica.

Nesse contexto, emerge a educação escolar indígena, que tem como desafio a construção de Histórias Indígenas. A concepção pósmoderna abre o espaço para a problematização das narrativas colonialistas. Assim, a valorização de narrativas indígenas que são historicamente fundadas sobre narrativas étnicas e locais, orientadas pelas formas de saber ancestrais, centradas nos problemas da soberania e inspiradas pelas profundas conexões entre a Terra, seus seres e o mundo espiritual, é uma possibilidade enriquecedora para o ensino de História. 


\section{NOTAS}

1 Informação do site do Instituto Socioambiental (ISA). Disponível em: http://pib.socioambiental.org/pt/povo/Maxakali/770. Acesso em: 02 out. 2012.

2 A Praça da Liberdade passou, assim, de centro do poder executivo para centro de atividades culturais, educacionais e artísticas, por meio de parcerias entre instituições públicas e privadas - no caso do Espaço do Conhecimento, entre a empresa de telefonia móvel multinacional TIM e a Universidade Federal de Minas Gerais.

3 Disponível em: http://revista.fapemig.br/materia.php?id=199. Acesso em: 09 out. 2012.

4 A Lei n 11.645, de 10/03/2008, tem o mesmo texto da Lei n ${ }^{\circ}$ 10.639, de 09/01/2003, que tornou obrigatório o ensino de História e Cultura Afro-Brasileira na Educação Básica com o acréscimo do termo "Indígena". (Disponível em: http://www.planalto.gov.br/ccivil_03/leis/2003/L10.639.htm. Acesso em: 06 nov. 2012).

5 Instituto Nacional de Estudos e Pesquisas Educacionais Anísio Teixeira (INEP). Edital no 3, 24/05/2012, para o Exame Nacional do Ensino Médio (ENEM). Disponível em: http://download.inep.gov.br/educacao_basica/enem/edital/2012/edital-enem2012.pdf. Acesso em: 04 dez. 2012.

6 “Capítulo VIII: Dos Índios”. In: BRASIL. Constituição da República Federativa do Brasil. Disponível em: http://www.planalto.gov.br/ccivil_03/constituicao/constituicao.htm. Acesso em: 04 dez. 2012.

\section{REFERÊNCIAS}

ANHORN, Carmen Tereza Gabriel. Um objeto de ensino chamado História: a disciplina de história nas tramas da didatização. 2003. Tese (Doutorado em Educação) - Pontifícia Universidade Católica, Rio de Janeiro.

ARAÚJO, Ricardo Benzaquen. História e narrativa. Revista do Departamento de História, Minas Gerais, v. 1, n. 11, p.57-75, 1992.

BARTHES, Roland. Introdução à análise estrutural das narrativas. In: A aventura semiológica. Trad. Mário Laranjeira. São Paulo: Martins Fontes, 2001. p.103-152.

BICALHO, Charles Antônio de Paula. Narrativas orais Maxakali: uma proposta de transcrição e análise. Albuquerque: Universidade do Novo México, 2004.

BRASIL. Constituição da República Federativa do Brasil. Brasília: Senado Federal, 1988.

BRASIL. Parâmetros Curriculares Nacionais: terceiro e quarto ciclos do ensino fundamental. Brasília: MEC/SEF, 1997.

BROCKMEIER, Jens; HARRE, Rom. Narrativa: problemas e promessas de um paradigma alternativo. Psicologia: Reflexão e Crítica, Porto Alegre, n.16 (3), p.525-535, 2003. COELHO, Maria do Carmo Pereira. As narrações da cultura indígena da Amazônia: lendas e histórias. 2003. Tese (Doutorado em Linguística) - Pontifícia Universidade Católica, São Paulo. 
FONSECA, Thais Nívia de Lima e. História \& ensino de História. Belo Horizonte: Autêntica, 2003.

FOUCAULT, Michel. A arqueologia do saber. Petrópolis, (RJ): Vozes; Lisboa: Centro do Livro Brasileiro, 1972.

GRANDE, Sandy. Red pedagogy: native American social and political thought. Lanham: Rowman \& Littlefield, 2003.

INSTITUTO Nacional de Estudos e Pesquisas Educacionais Anísio Teixeira (INEP). Edital no 3, 24/05/2012 para o Exame Nacional do Ensino Médio (ENEM). Disponível em: http://download.inep.gov.br/educacao_basica/enem/edital/2012/edital-enem2012.pdf. Acesso em: 04 dez. 2012.

KRENAK, Ailton. História indígena e o eterno retorno do encontro. In: LIMA, Pablo (Coord.). Fontes e reflexões para o ensino de história indígena e afrobrasileira: uma contribuição da área de história do PIBID/FAE/UFMG. Belo Horizonte: UFMG/FaE, 2012. p.122.

LABOV, William; WALETZKY, Joshua. Narrative analysis: oral versions of personal experience. In: HELM, J. Essays on the verbal and visual arts. Seattle: University of Washington Press, 1967. p.12-44.

LATHER, Patty. Critical pedagogy and its complicities: a praxis of stuck places. Educational Theory, v.48, n.4, 1998, p.431-62.

LE GOFF, Jacques. História e memória. Campinas: Editora Unicamp, 1990.

LINHART, Jan. A interculturalidade no contexto do ensino superior e as suas implicações epistemológicas. Tabebuia - Índios, Pensamento e Educação, Belo Horizonte, Literaterras/UFMG, ano 2, p.268-285, 2012.

MAXAKALI, Rafael et al. Penãhã: livro de Pradinho e Água Boa/Povo Maxakali. Belo Horizonte: FALE/UFMG, 2005.

MENDES, Patrícia M. Mudanças e continuidades: os aspectos da organização social Maxakali. Juiz de Fora: UFJF, 2009. [Monografia].

POPOVICH, Frances B. A organização social dos Maxakali. Cuiabá: Sociedade Internacional de Linguística, 1980.

PROUS, André. O Brasil antes dos brasileiros: a pré-história do nosso país. Rio de Janeiro: Jorge Zahar, 2007.

RICOEUR, Paul. Tempo e narrativa. Campinas: Papirus, 1997. v.3.

SHAPIRO, Svi. Educational change and the crisis of the left: toward a postmodern educational discourse. In: KANPOL, Barry; McLAREN, Peter (Eds.). Critical multiculturalism: uncommon voices in a common struggle. Westport: Bergin and Garvey, 1995. p.19-38. 
Recebido: 09/01/2013

Aprovado: 19/08/2013

Contato:

Faculdade de Educação Universidade Federal de Minas Gerais Avenida Antônio Carlos, 6627

Pampulha

CEP 31270-901

Belo Horizonte | MG | Brasil 